\title{
A Dimensionless Measure of Filter Selectivity: Geometrical Factors in Cigaret Construction which Influence this Measure*
}

\author{
by $H$. Davis and W. George
}

Summit Research Laboratories, Celanese Corporation of America, Summit, N. J., USA

A rational definition for characterizing the capacity of a cigaret filter to selectively modify the chemical composition of mainstream smoke is presented. The definition is related to the concept of separation factor as defined in chemical engineering and applied in the description of various unit processes.

A number of numerical values for a wide range of cigaret filters currently found in the world market place are presented. The relative independence of the selectivity as defined in this paper upon tobacco types is demonstrated.

Using a fixed filter construction in terms of amount and type of cellulose acetate fiber and plasticizer content, selectivity values are presented as a function of cigaret length and relative proportion of the cigaret which is allotted to the filter. Further, it is shown that selectivity appears to increase with length for given filter construction parameters. A limited amount of data regarding selectivity for weak acid components of mainstream smoke and certain gas phase components is presented as a characterization of dual filters currently on the US market.

INTRODUCTION

Over the past several years a number of papers have appeared which discuss the phenomenon of "selective" alteration of mainstream cigaret smoke by various cigaret filters. In these works, one observes the composition of the smoke from an all tobacco cigaret and compares it with that of the mainstream delivered from the cigaret with a filter attached. If the concentration of the smoke components of interest is not altered by the filtration process, one then observes no selective reduction, only a certain reduction in the total amount of smoke delivered. On the other hand, if the concentration of one or another component is altered to a greater extent than all others, then we may speak of selective alteration. If the concentration is reduced, based upon the total amount of smoke, or some other suitable normalization, we speak of "selective" reduction or filtration.

In principle, the amount of a component might be increased through filtration. Should this be

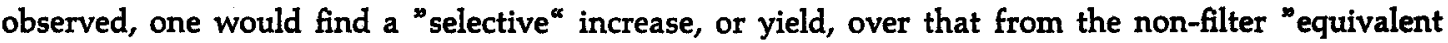
cigaret". It is obvious that much attention to definition of experimental equivalence will be required in this situation. No further comment on this point will be made in this paper.

- Presented to the 5th General Assembly of the CORESTA. Vienna, October 1964 
The earliest suggestions of filter selectivity are found in the work of Haag and Larson (1959) (1). These workers noted that certain activated carbons could be incorporated in a cigaret filter to reduce the amount of certain "gas phase ${ }^{\alpha}$ irritants in the mainstream smoke. A few years later, Hoffmann and Wynder (1963) (2) noted that commercial cellulose acetate filters permit the selective reduction of weakly acidic components normally present in the mainstream of cigaret smoke. The present authors have discussed the nature of these effects (3). Spears (4) published additional observations in this area. Keith (5) and Williamson (6) extended the observations of Haag and Larson, using both model systems and mainstream tobacco smoke.

The practical interest in selectively altering mainstream cigaret smoke, in part, has been driven by the results of toxicological studies, together with experimental animal carcinogenesis experiments. The weakly acidic substance which cellulose acetate filters selectively reduce or remove from mainstream smoke were shown by Boutwell and Bosch (7) to be promoters for the production of laboratory induced tumors, using the skin of mice. These observations have been extended by $W y n d e r$ and co-workers (8).

The early work of Haag and Larson contained the observation that edema could be induced in the eyelids of rabbits by the so-called "gas phase ${ }^{\alpha}$ of mainstream cigaret smoke. These workers showed that a charcoal-containing paper based dual filter could be effective in reducing the sources of this biological effect. Work by Irby and Harlow (9) on the composition changes in the "gas phase" of such filtered smoke showed that a reduction was being effected in the amount of a number of aldehydes and ketones among other "gas phase" components in the smoke.

More recently, the ciliatoxic nature of many compounds found in mainstream cigaret smoke appears to have encouraged further examination of ways and means to selectively modify this smoke $(10,11,12,13)$. It is perhaps worth emphasizing that the weakly acidic components of mainstream cigaret smoke, singly and in combination, are capable of inhibiting normal ciliary activity in tissue derived from a wide range of animals, including man. A similar effect is noted for many "gas phase" smoke components.

A simple means of characterization of selectivity cannot be found in the early work cited above. Accordingly, the present authors felt that a new attempt at defining a general measure of selectivity merited serious consideration. In casting about for such a measure we were intrigued by the concept of separation factor which is used in the chemical industry as an index of the effectiveness of a distillation column as well as a number of similar schemes which permit the purification of a particular compound from an impure feed stream such as permeation and extraction, etc. In all of these cases the chemical engineer has found it convenient to describe the effectiveness of the separation in terms of a dimensionless ratio, sometimes called a separation factor (14). In the processes mentioned here separation factors are positive. The lower the value of the factor, the more effective the separation. Since enrichment of a feed stream is usually of prime interest in the engineering processes we have mentioned, the dimensionless separation factor commonly employed emphasizes this aspect. The manner in which this is done utilizes as a definition of the separation factor, say $\beta$, the following expression:

$$
\beta=\frac{\text { Concentration in feed stream }}{\text { Concentration in product stream }}
$$

If enrichment is accomplished by such a process it is clear that $\beta$ values are always between $I$ and $o$ : the smaller $\beta$, the more complete the separation.

We find it convenient to invert the scheme of eq ( 1 ) above in devising a "selectivity" factor to describe the depletion in concentration of mainstream smoke by the selective removal of various components by a selective filter. We, therefore, adopt the following as a definition of selectivity factor to describe the desired property of a cigaret filter:

$$
S_{x}=\frac{\text { Concentration of } x \text { in "equivalent }{ }^{\text {" unfiltered smoke }}}{\text { Concentration of } x \text { in filtered smoke }}
$$

If a filter performs no differently than the "equivalent", all-tobacco cigaret with respect to modifying $x$, selectivity is not present and $S_{x}=1$. If the filter is less selective than the all-tobacco cigaret, $S_{X}<1$. In all cases where some element of selectivity is present in a filter, $S_{X}>_{1}$. 
It has been our purpose in designing a dimensionless ratio to characterize the selectivity of a cigaret filter to attempt a definition which, in principle, should be insensitive to, if not independent of, the amount and type of smoke passed by the filter either under conditions of smoking to a constant length of standard tobacco, or with respect to the yield per puff. As will be shown, the number fulfills part of this goal.

This definition (eq [2]) can be more explicitly written as:

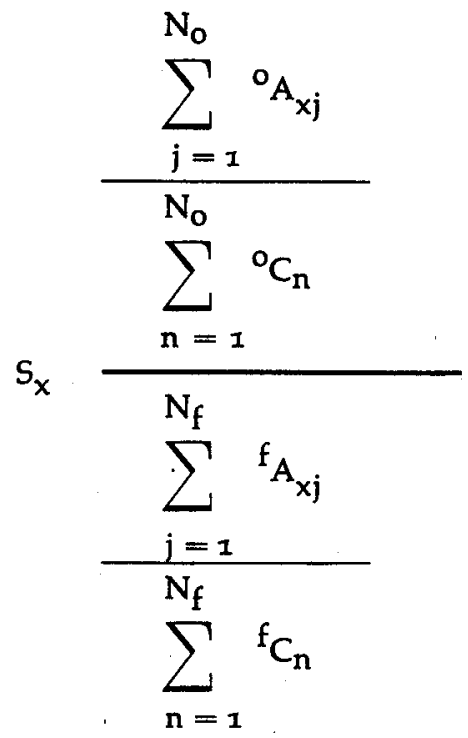

In eq (3), the superscript $\left({ }^{\circ}\right)$ refers to the standard (non-filter) equivalent all-tobacco cigaret, while $\left({ }^{f}\right)$ refers to the filter cigaret whose selectivity for component $x$ is sought. The symbol ${ }^{k_{A j}}$ denotes the weight of component $x$ for cigaret $k=0, f$ contributed by puff $j$. The summation is taken over the number of puffs used in the comparison.

$N_{0}$ refers to the puff number required to smoke the all-tobacco control to the arbitrary end point used in the comparison, while $\mathrm{N}_{\mathrm{f}}$ similarly refers to the filter cigaret under study. The symbols ${ }^{k} C_{n}$ refer to the weight of condensate trapped in the smoking experiment. The values of $k=0$, $f$ are as before, and the values of $j$ range over the number of puffs, either $N_{o}$ or $N_{f}$.

In this terminology the efficiency, $E$, of the filter in removing whole smoke is a function of ${ }^{k} C_{n^{\prime}}$ as shown below, in terms of the fractional reduction of condensate:

$$
E=\frac{\sum_{n=1}^{N_{0}}{ }^{o} C_{n}-\sum_{n=1}^{N_{f}}{ }^{f} C_{n}}{\sum_{n=1}^{N_{0}}{ }^{o} C_{n}}
$$

From both the above definitions it is seen that the condition $N_{o}=N_{f}$ will simplify the formulas somewhat; however, as is commonly done, smoking to fixed butt lengths will in general make $\mathrm{N}_{\mathrm{o}} \neq \mathrm{N}_{\mathrm{f}}$

It is seen that estimates for fixed numbers of puffs or on a per puff basis can in principle be made from the above formula for selectivity, $s_{x}$. However, for many of those compounds commonly found in the "particulate" phase of cigaret smoke, the estimation is analytically difficult due to 
practical considerations. On the other hand, it is relatively easy to measure on a per puff basis the amounts of compounds present in the so-called "gas phase". For example, all material passed by a standard Cambridge trap may be termed "gas". In our laboratories we experience no difficulty in measuring the necessary quantities to provide a selectivity value for substances such as acetaldehyde, acrolein, etc., under the indicated definition.

It should be noted that in defining the selectivity number proposed here that a total smoke condensate is used. In the case of per puff selectivity the value for normalization, of necessity due to practical considerations, is some type of average obtained either from many puffs or a given puff from many cigarets.

Selectivity as defined here is closely inter-related to the fractional reduction of smoke by the filter, $E$. In fact, it is related through the fractional reduction of the compound $x, R_{x}$. The latter may be defined as:

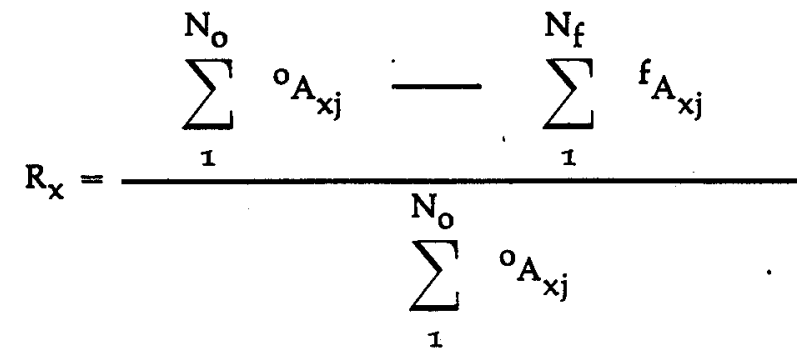

With this definition of $R_{X}$, and $E$ as defined previously,

$$
S x=\frac{I-E}{1-R_{X}}
$$

This relation can be visualized through the aid of Figure $I$, which plots $R_{x}$ vs $E$ for various levels of $S_{\mathbf{x}}$.

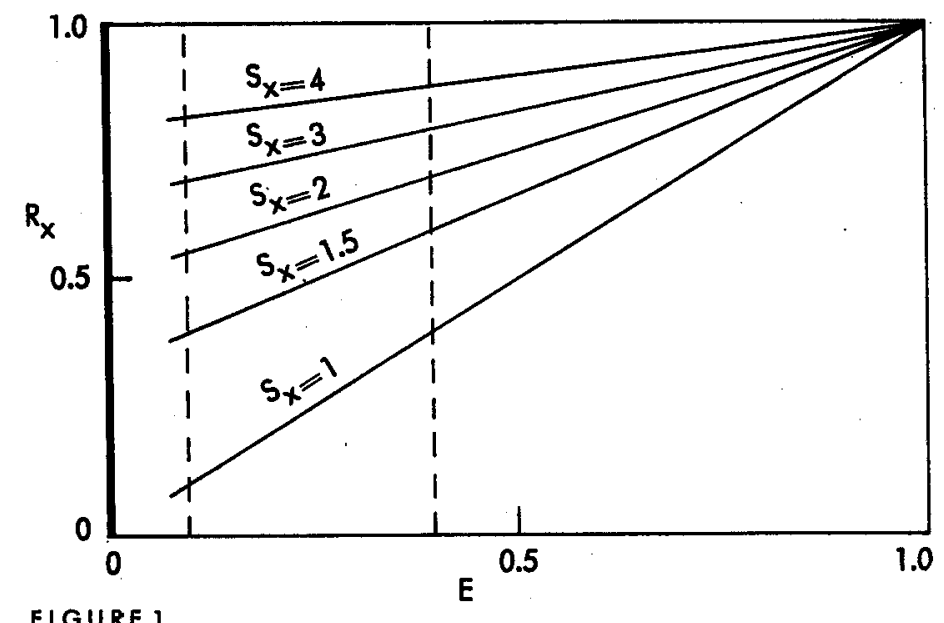

FIGURE 1
Most practical cigaret filters possess $E$ values below 0.5. Accordingly, $E$ and the selectivity number, or $R_{X}$, provide a description of the filter in terms of a point lying above the line labeled $S_{x}=$ 1 , and roughly between the two dashed vertical lines.

We have found that the measurement of condensate is most readily obtained by trapping the smoke at $-80^{\circ} \mathrm{C}$, capping the trap loosely and warming it to room temperature prior to weighing.

It is clear that all or part of certain highly volatile materials which are trapped initially do not appear

in the condensate weight used in normalization. Further, the substance in the trap includes moisture initially present in the air used during the smoking process. The latter is maintained constant in our smoking laboratory with good precision at $60 \pm 2 \% \mathrm{R}$. H., at a temperature of $72 \pm x^{\circ} \mathrm{F}$.

It is possible to refer selectivity to tobacco used by a particular cigaret manufacturer on one hand, and on the other to an arbitrarily chosen standard tobacco column. Values obtained in these two ways for three commercial filter tips found on three popular US cigarets as produced during 1963 are shown in Table 1.

These selectivities refer to the selective removal of phenol by the listed filters. It is felt that the characterization of phenol selectivity is perhaps more direct and straightforward if one bases this 
upon a standard tobacco column. The phenol determination is based on the method described by Hoffmann and Wynder (15) with minor modifications which greatly facilitate the collection of data and do not seriously impair the absolute reliability of the phenol determination. After the weak acid fraction is separated from the total condensate, the phenols, including the cresols, are determined by gas chromatography with a Perkin-Elmer Model 226 gas chromatograph equipped with flame ionization detector and a $100 \mathrm{ft}$. capillary column, 0.02 " internal diameter, coated with $85 / 15$ Cellulube 550/Dimer acid. This column was suggested to us by Dr. D. Hoffmann of the Sloan-Kettering Institute, New York, and has proved highly reliable for industrial laboratory work. Other acid fraction components-acetic, propionic, butyric acid, etc. - can also be resolved with this column.

A larger number of commercial cigaret filters produced in the United States have been characterized with regard to their ability to selectively filter phenol from the mainstream smoke. A standard tobacco column and an $85 \mathrm{~mm}$ overall cigaret length were used. All cigarets were smoked to a $25 \mathrm{~mm}$ butt length. These values are presented in Table 2.

It is possible to use the same filters listed in Table 1 to characterize their selectivity for removing ortho, meta, and para-cresols. The selectivity values obtained for the removal of the sum of these compounds are shown in Table 3.

Empirically, we have found in commercial acetate filter tow fabricated by commercial processes into rods that the pressure drop per se of tips cut therefrom does not exert a major influence upon the selectivity; in other words, filter parameters other than pressure drop exert a much greater influence. Similarly, tobacco types as shown in Tables 1 and 3, do not appear to contribute in a major way to variation in the selectivity values measured. A small amount of data is available concerning similar tips studied by two different laboratories, namely, the Celanese Research Laboratories and the laboratories of Dr. Wynder at the Sloan-Kettering Institute. The latter used a somewhat different method for estimating condensate, as well as a different smoking procedure. These differences are within the range of practical variations that may be encountered in attempting to obtain selectivity values at various laboratories equipped with different smoking machines and different standardized procedures. Nonetheless, the selectivity number defined in this paper can be computed so long as individual laboratory procedures are internally consistent. It is perhaps surprising, but nonetheless true, when this type of consistency is present, that the selectivity values for a given filter are remarkably similar, as indicated in Table 4.

Workers at both the Sloan-Kettering Institute (2) and the P. Lorillard Company (4) laboratories have noticed that the removal of phenol from the mainstream smoke is related to the age of the filter rods used in cigaret manufacture. These ageing effects, as reported in the literature, appear to saturate after approximately one month of ageing. Another type of ageing effect has been observed
Phenol selectivity of filter tip on different tobacco columns

\begin{tabular}{c|c|c}
\cline { 2 - 3 } & \multicolumn{2}{|c}{$\begin{array}{c}\text { Phenol selectivity } \\
\text { value, S }\end{array}$} \\
\hline Filter & $(1)^{*}$ & $(2)^{* *}$ \\
\hline Cigaret B & 3.3 & 3.1 \\
Cigaret O & 2.7 & 2.9 \\
Cigaret E & 2.8 & 2.8 \\
\hline
\end{tabular}

* Determined with its own tobacco column

** Determined with standard tobacco column, Cig. A

TABLE 2

Phenol selectivity values of commercial cigaret filters

\begin{tabular}{l|c}
\hline \multicolumn{1}{c|}{ Filter } & $\begin{array}{c}\text { Phenol } \\
\text { selectivity value, S }\end{array}$ \\
\hline Cigaret $\mathrm{E}$ & 2.8 \\
Cigaret $\mathrm{N}$ & 2.8 \\
Cigaret $\mathrm{H}$ & 3.2 \\
Cigaret $\mathrm{B}^{*}$ & 3.2 \\
Cigaret $\mathrm{O}$ & 2.8 \\
Cigaret $\mathrm{L}^{*}$ & 2.0 \\
Cigaret $\mathrm{M}^{*}$ & 1.5 \\
Cigaret $\mathrm{Y}$ & 1.6 \\
Cigaret Z & 1.9 \\
Cigaret $\mathrm{X}$ & 3.3 \\
\hline
\end{tabular}

TABLE 3

Cresol selectivity of filter tip on different tobacco columns

\begin{tabular}{c|c|c}
\cline { 2 - 3 } & \multicolumn{2}{|c}{ Cresol selectivity, S } \\
\hline Filter & $(1)^{*}$ & $(2)^{* *}$ \\
\hline Cigaret B & 2.3 & 2.5 \\
Cigaret O & 2.1 & 1.9 \\
Cigaret E & 2.2 & 2.3 \\
\hline
\end{tabular}

* Determined with its own tobacco column

** Determined with standard tobacco column, Cig. A 
over a much longer time scale. This involves the change in selectivity value for filters cut from rods over a period of about one year. In this case it is reasonable to presume that the plasticizer applied during rod manufacture has had adequate time to reach equilibrium throughout the individual fibers

\begin{tabular}{|c|c|c|}
\hline \multirow[b]{2}{*}{ Filter } & \multicolumn{2}{|c|}{ Phenol selectivity value, $\mathbf{S}$} \\
\hline & $\begin{array}{c}\text { Calculated from } \\
\text { Hoffmann } \\
\text { and Wynder } \\
\text { data }\end{array}$ & Our data \\
\hline Cigaret E & 2.9 & 2.8 \\
\hline $\begin{array}{l}\text { Experimental triacetate } A \text {, } \\
5 \% \text { plasticizer }\end{array}$ & 2.4 & 2.4 \\
\hline Secondary acetate, unplasticized & 1.9 & 2.1 \\
\hline $\begin{array}{l}\text { Secondary acetate } \\
5 \% \text { plasticizer }\end{array}$ & 2.3 & 2.3 \\
\hline
\end{tabular}

TABLE 4

as well as to become reasonably uniformally dispersed amongst the fibers in the filter. The effect of this uniformizing of plasticizer content which is surely accomplished by normal diffusion processes is to substantially reduce the selectivity of the filter for at least phenol. Values for the freshly - manufactured tips measured by us of 3.0 were reduced to 2.3 on storage of the rods in the absence of tobacco for a period of about one year.

Neurath (1964) (16) has reported the generally high yield of phenol in tobacco smoke which is conditioned and smoked at low relative humidity and compared with the generally lower yield from

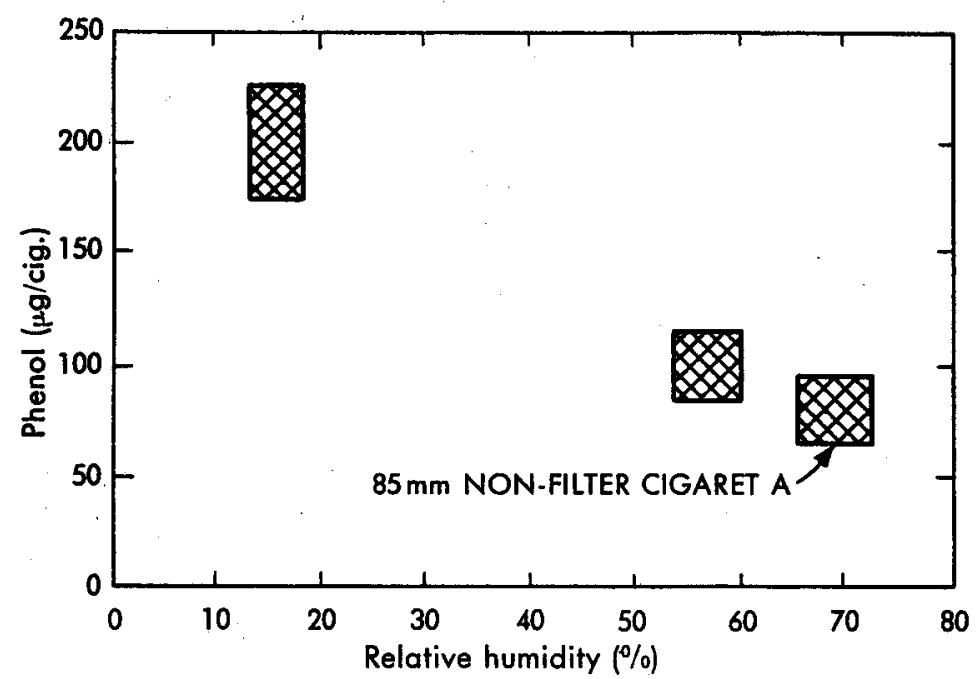
tobacco when smoked and conditioned at higher relative humidity. We have made similar measurements under conditions where the various phenols were clearly separated and measured. Results obtained in this study are shown in Figure 2.

FIGURE 2

Effect of moisture in cigarel upon phenol lovel in smoke (temperature: $72^{\circ} \pm 2 \circ \mathrm{F}$ )

When filter cigarets were similarly conditioned and smoked a value of selectivity is obtained which is characteristic of the relative humidity of the experiment as indicated in Table 5.

Spears (4) and the Sloan-Kettering workers Wynder and Hoffmann (2) have reported the effect of

\begin{tabular}{l|c|c}
\hline \multicolumn{1}{c|}{ Filter } & \multicolumn{2}{c}{ Phenol selectivity value, S } \\
\hline & $\begin{array}{c}15 \%-20 \% \\
\text { relative } \\
\text { humidity }\end{array}$ & $\begin{array}{c}60 \% \\
\text { relative } \\
\text { humidity }\end{array}$ \\
\hline CFL 726 & 1.9 & 2.3 \\
CFL 731 & 1.7 & 2.3 \\
CFL 730 A - unplasticized & 1.2 & 1.8 \\
CFL 724 A - unplasticized & 1.4 & 2.1 \\
\hline
\end{tabular}
type of plasticizer upon phenol selectivity. Their data are not presented in terms of the definitions of this paper, but can be converted. It is clear from these workers that the type of plasticizer, as well as the amount, particularly the latter, applied to the tip during manufacture, is a major

TABLE 5 Effect of moisture on phenol selectivity 
factor in determining the phenol selectivity for cellulose acetate tow based tips. Similar data have been obtained by us and a typical selection of these is presented in Table 6 .

We have made a study of the effect of filter length relative to the tobacco column length upon the selectivity number $S_{x}$. The tobacco columns were cut from $85 \mathrm{~mm}$, non-filter US cigarets, graded for weight and pressure drop uniformity. The tips were cut from a carefully selected set of rods, having a fixed level of triacetin plasticizer and a uniform tow structure. The pressure drop per unit length of rod was fixed at $\Delta \mathrm{P} / \Delta \mathrm{L}=\mathbf{2 . 8}$ millimeters of $\mathrm{H}_{2} \mathrm{O} / \mathrm{mm}$ at a flow rate of $17.5 \mathrm{cc} / \mathrm{min}$. Three different geometrical cases were considered in this work, Cases A, B and C. In the first, Case $A$, a fixed tobacco length was tipped with three different length sections, cut from the above-described filter rods. These lengths are shown in Table 7 . In Case B, a fixed cigaret length of $85 \mathrm{~mm}$ was maintained and the three filter lengths were added to variable lengths cut from the tobacco columns. These are shown in Table 8.

The filter rods used in this experiment were relatively old, so that no timewise variations are expected in the data which were accumulated over a period of several months.

TABLE 6

Effect of plasticizer lovel on phenol selectivity value, $\mathbf{s}$

\begin{tabular}{l|r|c}
\hline \multicolumn{1}{c|}{ Filter } & Plasticizer & $\mathrm{S}$ \\
\hline CFL 720's & $0 \%$ GTA & 2.1 \\
Acetate & $6 \%$ GTA & 2.3 \\
& $14 \%$ GTA & 3.1 \\
CFL 730's & $0 \%$ GTA & 1.9 \\
(Experimental) & $6 \%$ GTA & 2.3 \\
(Triacetate) & $12 \%$ GTA & 2.9 \\
& $6 \%$ GTA & 2.5 \\
TA 1814: & $12 \%$ GTA & 2.9 \\
(Acetate) & $0 \%$ GTA & 1.9 \\
& $7.8 \%$ GTA & 3.2 \\
X: & $(0 \%$ TEC & $(2.0)$ \\
(Acetate) & $10 \%$ TEC & 3.1 \\
& $15 \%$ TEC & 4.1 \\
\hline 50800-10: &
\end{tabular}

Effect of filier tip length on phenol selectivity value, $S$ (Case A)

\begin{tabular}{l|l|l|l|l|c|c|c}
\hline \multicolumn{1}{c|}{ Cigaret } & $\begin{array}{c}\text { Filtertip } \\
\text { length }\end{array}$ & $\begin{array}{c}\text { Total } \\
\text { cigaret } \\
\text { length }\end{array}$ & $\begin{array}{c}\text { Length } \\
\text { smoked }\end{array}$ & $\begin{array}{c}\text { Phenol } \\
\mu \mathrm{g} / \mathrm{cig} .\end{array}$ & $\begin{array}{c}\text { Condensate } \\
\mathrm{mg} / \mathrm{cig} .\end{array}$ & $\begin{array}{c}\mu \mathrm{m} \text { phenol } \\
\mathrm{mg} / \text { conden- } \\
\text { sate }\end{array}$ & $\mathrm{S}$ \\
\hline \multirow{2}{*}{ Filter: } & $10 \mathrm{~mm}$ & $78 \mathrm{~mm}$ & $60 \mathrm{~mm}$ & $50 \pm 2$ & $46 \pm 3$ & 1.09 & 2.1 \\
& 15 & 83 & 60 & $35 \pm 3$ & $39 \pm 3$ & 0.90 & 2.3 \\
& 20 & 88 & 60 & $32 \pm 4$ & $38 \pm 2$ & 0.84 & 2.6 \\
All & & 78 & 60 & $121 \pm 7$ & $53 \pm 4$ & 2.3 & - \\
tobacco & - & 83 & 60 & $101 \pm 4$ & $48 \pm 3$ & 2.1 & - \\
& - & $(85)$ & $(60)$ & $(89)$ & $(41)$ & $(2.2)$ & - \\
& - & 88 & 60 & $91 \pm 7$ & $40 \pm 3$ & 2.3 & - \\
\hline
\end{tabular}

Effect of filter length on phenol selectivity value, $S$

TABLE 8 (Case B)

\begin{tabular}{l|l|l|l|l|l|l|l}
\hline \multicolumn{1}{|c|}{ Cigaret } & $\begin{array}{c}\text { Filter tip } \\
\text { length }\end{array}$ & $\begin{array}{c}\text { Total } \\
\text { cigaret } \\
\text { length }\end{array}$ & $\begin{array}{c}\text { Length } \\
\text { smoked }\end{array}$ & $\begin{array}{c}\text { Phenol } \\
\mu g / c i g .\end{array}$ & $\begin{array}{c}\text { Condensate } \\
\text { nig/cig. }\end{array}$ & $\begin{array}{c}\mu \mathrm{m} / \text { phenol } \\
\text { mg/conden- } \\
\text { sate }\end{array}$ & $\mathrm{S}$ \\
\hline Filter: & $10 \mathrm{~mm}$ & $85 \mathrm{~mm}$ & $60 \mathrm{~mm}$ & $64 \pm 2$ & $40 \pm 2$ & 1.60 & 1.35 \\
& 15 & 85 & 60 & $43 \pm 2$ & $41 \pm 2$ & 1.05 & 2.1 \\
All & 20 & 85 & 60 & $31 \pm 1$ & $40 \pm 2$ & 0.78 & 2.8 \\
tobacco: & - & 85 & 60 & 89 & 41 & 2.17 & - \\
\hline
\end{tabular}


From Table 7 it is immediately apparent that phenol selectivity increases with increasing filter tip length. The $20 \mathrm{~mm}$ tip shows a significantly higher phenol selectivity than the $10 \mathrm{~mm}$ or $15 \mathrm{~mm}$ tip. It is pertinent to note that $20 \mathrm{~mm}$ filter tip cigarets have recently appeared in the US retail market.

Tobacco shows no selectivity for phenol by definition. The amount of phenol found is directly proportional to the amount of condensate, within experimental error, for all lengths of the standard all-tobacco column. The value is $2.2 \pm 0.1 \mu \mathrm{g} / \mathrm{mg}$. The values in parenthesis are those for an $85 \mathrm{~mm}$ cigaret (the commercially manufactured standard tobacco column) obtained some six months prior to the data in the tables.

Case B, Table 8, is thought to be a more practical demonstration of the effect of filter tip length on phenol selectivity than Case A. Again, it is seen that phenol selectivity increases with increasing filter tip length. The $S$ value of 2.8 for the $20 \mathrm{~mm}$ tip is significantly higher than the $S$ values of 2.1 and 1.35 , respectively, for the $15 \mathrm{~mm}$ and $10 \mathrm{~mm}$ tips. In either case, greater selective filtration is achieved with increasing filter tip length. It would follow from the above that a higher phenol selectivity could be achieved with a $25 \mathrm{~mm}$ tip.

Finally, in Case $C$, an optimum combination of filter tip length and tobacco column length was sought. Filter tip lengths of 10,15 , and $20 \mathrm{~mm}$ were studied in cigarets with overall lengths of 70,78 , and $85 \mathrm{~mm}$, respectively. All cigarets were smoked to a $25 \mathrm{~mm}$ butt length - this includes the filter tip. The filter was the same as before.

Phenol selectivity values were determined in the manner described and are tabulated in Table $g$.

TABLE 9 Phenol selectivity value, $S$ (Case C)

\begin{tabular}{c|c|c|c|c}
\cline { 2 - 5 } & \multicolumn{4}{|c}{ Overall cigaret length } \\
\hline Tip length & $\begin{array}{c}\text { (1) } \\
70 \mathrm{~mm}\end{array}$ & $\begin{array}{c}\text { (2) } \\
78 \mathrm{~mm}\end{array}$ & $\begin{array}{c}\text { (3) } \\
\text { (3) }\end{array}$ & $\overline{\mathrm{x}}_{\mathrm{r}}$ \\
\hline (1) $10 \mathrm{~mm}$ & 1.7 & 1.6 & 1.4 & 1.6 \\
(2) $15 \mathrm{~mm}$ & 2.4 & 2.0 & 2.0 & 2.1 \\
(3) $20 \mathrm{~mm}$ & 2.8 & 3.0 & 2.8 & 2.9 \\
$\bar{x}_{\mathrm{c}}$ & 2.3 & 2.2 & 2.1 & - \\
\hline
\end{tabular}

The values $\bar{X}_{r}$ and $\bar{X}_{c}$ refer to the row and column averages, respectively. The standard deviation for an individual $S$ value is about 0.15 . The column averages, $\bar{X}_{c}$ 's, reflect the possible existence of an optimum combination of filter tip length and tobacco column length under the smoking program employed in this study. The average value $\bar{X}_{c}=2.3$ for column 1 is not much different than 2.1 for column 3 ; different at the $90 \%$ confidence level. The row averages, however, demonstrate, the previously described increase in selectivity with increasing filter tip length.

There has been, during the past year, renewed interest in filters which possess the capacity to remove certain "gas phase" constituents of mainstream smoke. One type of such tip is fabricated from activated carbon, fused into a porous plug with a polyolefin bonding agent. These tips are then incorporated as part of a dual filter. Another type involves the use of loose carbon held in place by two sections of acetate tow based tips. Both of these types of multicomponent tips containing carbon possess the ability to selectively remove various components of the "gas phase". In the case of the loose carbon bed type, a rather comprehensive listing of the compounds selectively removed from the "gas phase" has been reported by Keith (1963). We have measured the phenol selectivity of both types and found the results tabulated in Table 10.

We have found recently that it is possible to obtain quite high phenol selectivity in dual filters with an overall length of $20 \mathrm{~mm}$, half of which contains a significant level of activated carbon to

\begin{tabular}{l|c|c}
\hline Filter & $\begin{array}{c}\text { Phenol } \\
\text { selectivity } \\
\text { value, S }\end{array}$ & $\begin{array}{c}\text { Cresol } \\
\text { selectivity } \\
\text { value, S }\end{array}$ \\
\hline Cigaret B & 3.2 & 2.4 \\
Cigaret L & 2.0 & 1.7 \\
Cigaret M & 1.5 & 1.4 \\
\hline
\end{tabular}
remove "gas" from mainstream smoke. When the backup acetate section is properly fabricated, the combination dual tip is observed to have a high phenol selectivity. This is to be contrasted with the generally low values displayed in Table 10. Table 11 summarizes these results.

TABLE 10

Selectivity values of commercial filter tips containing activated carbon 
Dual tip, $20 \mathrm{~mm}$ :

Part (a) $10 \mathrm{~mm}$ plasticized secondary acetate, 14\% triacetin total weight: $90 \mathrm{mg}$

Part (b) $10 \mathrm{~mm}$ lightly plasticized secondary acetate, $3.8 \%$ triacetin $70 \mathrm{mg}$ plus activated charcoal, $62 \mathrm{mg}$ total weight: $130 \mathrm{mg}$

Condensate - mg/cig. $\quad-29$

Phenol selectivity value, $S-5.0$

Cresol selectivity value, $\mathrm{S}-4.9$

Phenol selectivity of experimental dual tip

In conclusion we wish to emphasize the following:

1. A rational definition of selectivity is proposed.

2. The explicit relationship between the selectivity and the fractional reduction of the amount of condensate delivered by the filter has been developed in terms of the fractional reduction in the compound selectively reduced.

3. Typical values of selective reductions for phenol and cresol are presented for a wide range of filters available worldwide.

4. It is shown for a typical filter rod that phenol selectivity is increased by increasing the length of the filter section. There is a possibility that for a given filter rod and tobacco, that there is an optimum combination of filter length and cigaret length to yield maximum selectivity. More work is needed on this point.

5. Selectivity in the reduction of weakly acidic compounds is increased with increasing plasticizer content for the case of cellulose acetate tow.

Finally, we note that in principle the concept of selectivity can be extended to "gas phase* constituents of smoke. Certain dual filters have been observed to exhibit quite high selectivity for substances such as acrolein and acetaldehyde. These observations can be cast within the framework of selectivity as defined in this paper.

SUMMARY

A rational definition for characterizing the capacity of a cigaret filter to selectively modify the chemical composition of mainstream smoke is presented. The definition is related to the concept of separation factor as defined in chemical engineering and applied in the description of various unit processes.

A number of numerical values for a wide range of cigaret filters currently found in the world market place are presented. The relative independence of the selectivity as defined in this paper upon tobacco types is demonstrated.

Using a fixed filter construction in terms of amount and type of cellulose acetate fiber and plasticizer content, selectivity values are presented as a function of cigaret length and relative proportion of the cigaret which is allotted to the filter. Further, it is shown that selectivity appears to increase with length for given filter construction parameters. A limited amount of data regarding selectivity for weak acid components of mainstream smoke and certain gas phase components is presented as a characterization of dual filters currently on the US market.

\section{ZUSAMMENFASSUNG}

Für die Kennzeichnung der Fähigkeit eines Cigarettenfilters zur selektiven Veränderung der chemischen Zusammensetzung des Hauptstromrauches wird eine rationale Definition entwickelt, die sich von dem in der technischen Chemie gebräuchlichen und bei der Beschreibung der Entwicklung von Einheiten verschiedener Maßsysteme üblichen Konzept des Separationsfaktors herleitet. 
Es werden eine Reihe von Kennzahlen für eine große Anzahl von Cigarettenfiltern angeführt, die gegenwärtig auf dem Weltmarkt im Handel sind. An ihnen wird nachgewiesen, daß die in der vorliegenden Arbeit benutzte Definition die Selektivität von der Tabaksorte relativ unabhängig erscheinen läßt.

Die untersuchten Filter glichen sich hinsichtlich Menge und Sorte der verwendeten Celluloseacetatfaser und der Weichmacher. Die Selektivitätswerte werden als eine Funktion der Länge der Cigarette und des relativen Anteiles der Länge gezeigt, der auf den Filter entfällt. Weiterhin wird gezeigt, daß die Selektivität bei sonst gleichen Herstellungsparametern des Filters mit der Länge zuzunehmen scheint. An einigen Meßwerten wird die selektive Wirkung der zur Zeit in den Vereinigten Staaten gebräuchlichen Doppelfilter auf schwach saure Bestandteile des Hauptstromrauches und auf bestimmte Bestandteile der Gasphase gezeigt.

RESUME

Les auteurs présentent une définition rationnelle portant caractérisation de l'aptitude d'un filtre à cigarettes d modifier sélectivement la composition chimique de la fumée du courant principal.

Cette définition est rapportée à la notion de facteur de séparation, tel qu'il est défini dans le Génie chimique et appliqué à la description de divers processus unitaires.

On présente une série de valeurs numériques concernant une gamme étendue de filtres pour cigarettes normalement offerts par le marché mondial. On met en évidence un certain degré de nonliaison entre le facteur de sélectivité ainsi défini et le type du tabac.

Utilisant une structure de filtres définie en termes de quantité et type de fibres d'acétate de cellulose et de plastifiant, les valeurs de sélectivité sont présentées en fonction de la longueur de la cigarette et de la proportion de cette longueur qui est réservée au filtre. Il est montré ensuite que la sélectivité tend à augmenter avec la longueur, les paramètres de structure du filtre étant donnés. On rapporte quelques données concernant la sélectivité vis-à-vis des composés acides faibles de la fumée du courant principal et de certains composants de la phase gazeuse, en tant que caractérisation des filtres composites (dual-filters) actuellement en usage aux Etats-Unis d'Amérique.

Note Added In Proot

\section{COMPARISON BETWEEN THE "DIRECT" AND "INDIRECT" METHODS} FOR MEASURING CIGARET FILTER SELECTIVITY

There are two ways in which the efficiency of a cigaret filter can be expressed. On one hand the filter can be placed upon a tobacco column, smoked in a fixed fashion and the smoke yield compared with that obtained from some standard or "equivalent" unfiltered cigaret. If these yields are, respectively $Y_{F}$ and $Y_{0}$, the efficiency can be defined by:

$$
E=\frac{Y_{0}-Y_{F}}{Y_{0}}
$$

Alternately, one may smoke the given filter cigaret and measure the amount of smoke delivered, $C_{y}$, and the amount picked up by the filter $C_{f}$. In these terms, efficiency of the filter may be defined by:

$$
\varepsilon=\frac{C_{f}}{C_{f}+C_{y}}
$$

The method for measuring the efficiency, E, (Eq I) can be termed an indirect method, in that it involves comparison with some arbitrarily chosen "equivalent" cigaret. The method for measuring $\varepsilon$, (Eq 2), only requires smoking a given filter cigaret. This in part reflects a more direct determination of efficiency. 
Earlier, Davis and George (1964) have proposed a measure of the selective filtration which is related to the indirect method for measuring filter efficiency. In these terms, selectivity is defined by:

$$
S_{x}=\frac{\frac{a_{0}}{Y_{0}}}{\frac{a_{F}}{Y_{F}}}
$$

where $Y_{0}$ and $Y_{F}$ are defined above, and $a_{0}$ and $a_{F}$ refer to the amount of the component $x$, in the standard and test cigaret (filter) respectively.

More recently, Davis and George (1965, unpublished) have proposed an alternate definition for expressing selective filtration using the concepts implicit in the direct definition of filter efficiency, $\varepsilon$. This direct method expresses the selectivity as a partitioning of the amounts of components $x, a_{f}$ and $a_{y}$ found respectively on the filter and in the smoke yield. In these terms the selectivity, $\sigma_{x}$, can be defined as a dimensionless number through:

$$
\sigma_{x}=\frac{\frac{a_{f}}{C_{f}}}{\frac{a_{y}}{C_{y}}} .
$$

In both schemes for expressing selectivity (indirect and direct) the dimensionless number or index of selectivity is related algebraically to the corresponding efficiency and a ratio measuring the "efficiency" with which the component in question is filtered. In the case of the indirect measure

$$
S_{x}=\frac{1-E}{1-R_{x}}
$$

$$
\text { where } R_{x}=\frac{a_{0}-a_{F}}{a_{0}} \text {. }
$$

In the case of the direct scheme:

$$
\sigma_{x}=\frac{P_{x}}{\varepsilon} \frac{(I-\varepsilon)}{\left(I-P_{x}\right)}
$$

where the component efficiency $\varrho_{\mathrm{X}}$ is given by:

$$
P_{x}=\frac{a_{f}}{a_{f}+a_{y}} .
$$

The relation Eq 8 can be put in another form, as follows:

$$
\sigma_{x}=\frac{\left[\frac{1}{\varepsilon}-1\right]}{\left[\frac{1}{P_{x}}-1\right]}
$$

It is clear from this form that as the removal of the component, $x$, becomes more complete, $e_{x} \rightarrow 1$. In this event the partition selectivity $\sigma_{x} \rightarrow \infty$, if $\varepsilon$ remains finite and less than unity. A special case, where $\varepsilon \rightarrow 1$ as $\varrho_{X} \rightarrow 1$, leaves the selectivity, $\sigma_{X}$, indeterminate. Similarly, if $\varepsilon$ and $\varrho_{x}$ both approach zero, $\sigma_{x}$ becomes indeterminate. If the case of very low smoke removal efficiency with selectivity is considered, the formalism again contains a singularity. In such a region of low efficiency the indirect definition given by Eq 5 , is clearly preferable (if $\mathrm{E} \rightarrow 0, \mathrm{~S}_{X}$ remains finite, given $R_{\mathbf{x}}$. finite and less than unity).

These two schemes for defining selectivity can be collapsed into one common scheme if the "equivalent" cigaret can be chosen in a certain conceptual way. If one chooses to make the equivalent 
cigaret that, which yields smoke amounts and component amounts at the face of the filter equal to those effective in the case of direct selectivity or efficiency experiments, then it can be shown that

$$
\text { and } \begin{aligned}
E & \rightarrow \varepsilon \\
\mathrm{R}_{x} & \rightarrow \rho_{x} \\
\sigma_{x} & \rightarrow \frac{\rho_{x}}{\varepsilon} S_{x} .
\end{aligned}
$$

If, as is often the case, the "efficiency" of a filter in removing a component is greater than its overall smoke removal efficiency

$$
\sigma_{\mathrm{x}}>\mathrm{S}_{\mathrm{x}} \text {. }
$$

If the filter does not remove a component at all, but does reduce the overall smoke output,

$$
\sigma_{x} \cong 0
$$

(All those last comments refer to the case where the initial input into the filter is determined by $a_{0}$ and $Y_{0}$, as given below.)

$$
\left.\begin{array}{c}
a_{o}=a_{f}+a_{y} \\
Y_{o}=C_{f}+C_{y}
\end{array}\right\}
$$

The above discussion highlights the role of the "equivalent" cigaret in the definitions of selectivity and efficiency using the indirect method for experimental determinations. If this "equivalent" cigaret is so chosen to make $S_{x} \geqslant 1$, as is sometimes convenient, there is no simple relation between $S_{x}$ and $\sigma_{x}$. This case is useful practically when the pickup by the filter of smoke and/or a given component is small and difficult to measure. The direct definition of selectivity, $\sigma_{x}$, is of less value in this event, and the choice of the "equivalent cigaret" can be based upon other factors.

\section{REFERENCES}

1. Haag, H. B., Larson, P. S., and Finnegan, J. K.: A. M. A. Archives of Otolaryngology 69 (1959) 261.

2. Hoffmann, D., and Wynder, E. L.: Journal of the National Cancer Institute 30 (1963) 67; Beiträge zur Tabakforschung 2 (1963) 51.

3. Davis, H. J., and George, T. W.: On the Potential for the Selective Filtration of Cigarette Smoke by Cellulose Acetate Fiber (paper presented at the Sixteenth Tobacco Chemists' Research Conference, Richmond, Virginia, 1962).

4. Spears, A. W.: Tobacco Science 7 (1963) 76.

5. Norman, V., Newsome, J. R., and Keith, C. H.: Techniques for the Analysis of Tobacco Smoke Vapors (paper presented at the Seventeenth Tobacco Chemists' Research Conference, Montreal, Canada, 1963).

6. Williamson, J. T., and Allman, D. R.: Vapor Phase Analysis of Consecutive Puffs during the Smoking of a Cigarette (paper presented at the Seventeenth Tobacco Chemists' Research Conference, Montreal, Canada, 1963).

7. Boutwell, R. K., and Bosch, D. K.: Cancer Research 19 (1959) 413.

8. Wynder, E. L., and Hoffmann, D.: Cancer 14 (1961) 1306.

9. Irby, R. M., Jr., and Harlow, E. S.: Tobacco Science 3 (1959) 52.

10. Guillerm, R. G., Bardré, R., and Vignon, B.: Bulletin Académie Nationale de Médecine 145 (1961) 416.

11. Kensler, C. J., and Battista, S. P.: New England Journal of Medicine 269 (1963) i161.

12. Wynder, E. L., Kaiser, H. E., Goodman, D. A., and Hoffmann, D.: Cancer 16 (1963) 1222.

13. Wynder, E. L., and Hoffmann, D.: Advances in Cancer Research, New York, Academic Press, 1964.

14. Coulson, J. M., and Richardson, J. F.: Chemical Engineering, Volume II, Unit Operations, New York, McGraw-Hill, 1955, p. 751.

15. Hoffmann, D., and Wynder, E. L.: Beiträge zur Tabakforschung 1 (1961) 101.

16. Ehmke, H., and Neurath, G.: Beiträge zur Tabakforschung 2 (1964) 205.

The authors' address:

Celanese Corporation of America, Research Laboratories, Box 1000, Summit, New Jersey, USA 